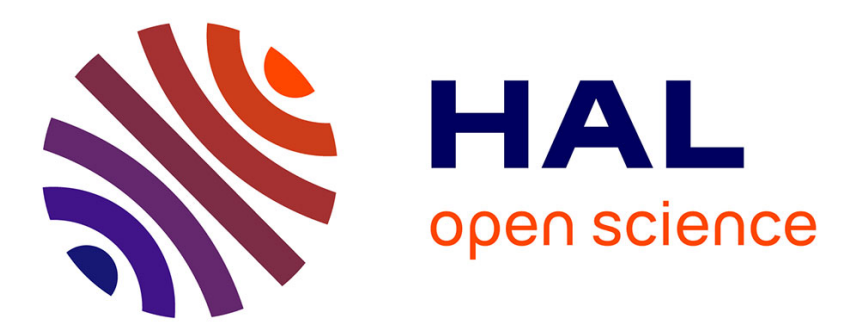

\title{
Monitoring of heavy metal particle emission in the exhaust duct of a foundry using LIBS
}

Christophe Dutouquet, Guillaume Gallou, Olivier Le Bihan, J.B. Sirven, Adrien Dermigny, B. Torralba, Emeric Frejafon

\section{- To cite this version:}

Christophe Dutouquet, Guillaume Gallou, Olivier Le Bihan, J.B. Sirven, Adrien Dermigny, et al.. Monitoring of heavy metal particle emission in the exhaust duct of a foundry using LIBS. Talanta, 2014, 127, pp.75-81. 10.1016/j.talanta.2014.03.063 . ineris-01862437

HAL Id: ineris-01862437

https://hal-ineris.archives-ouvertes.fr/ineris-01862437

Submitted on 27 Aug 2018

HAL is a multi-disciplinary open access archive for the deposit and dissemination of scientific research documents, whether they are published or not. The documents may come from teaching and research institutions in France or abroad, or from public or private research centers.
L'archive ouverte pluridisciplinaire HAL, est destinée au dépôt et à la diffusion de documents scientifiques de niveau recherche, publiés ou non, émanant des établissements d'enseignement et de recherche français ou étrangers, des laboratoires publics ou privés. 


\section{Monitoring of heavy metal particle emission in the exhaust duct of a foundry using LIBS}

Authors: C. Dutouquet ${ }^{\mathrm{a}}$, G. Gallou, ${ }^{\mathrm{a}, \mathrm{b}, \mathrm{c}, 1}$, O. Le Bihan ${ }^{\mathrm{a}}$, J.B. Sirven ${ }^{\mathrm{b}}$, A. Dermigny ${ }^{\mathrm{a}}$, B. Torralba ${ }^{\mathrm{d}}$ and E. Frejafon ${ }^{\mathrm{a}}$

${ }^{a}$ Institut National de l'Environnement Industriel et des Risques (INERIS / DRC / CARA / NOVA), Parc Technologique Alata, BP 2, 60550 Verneuil-En-Halatte, France

${ }^{\mathrm{b}}$ Commissariat à 1'Energie Atomique (CEA), Department of Physical Chemistry, F-91191 Gif-sur-Yvette, France

${ }^{c}$ Agence de l'Environnement et de la Maîtrise de l'Energie (ADEME), BP 90406, 49004 Angers, France

${ }^{\mathrm{d}}$ Centre Technique des Industries de la Fonderie (CTIF), F-92318 Sevres, France

${ }^{1}$ IVEA Solution, 91400 Orsay, France

Corresponding author: Christophe Dutouquet

christophe.dutouquet@ineris.fr

Tel.: +33 344618146

Fax: +33 344556872

\section{Abstract}

Heavy metals have long been known to be detrimental to human health and the environment. Their emission is mainly considered to occur via the atmospheric route. Most of airborne heavy metals are of anthropogenic origin and produced through combustion processes at industrial sites such as incinerators and foundries. Current regulations impose threshold limits on heavy metal emissions. The reference method currently implemented for quantitative measurements at exhaust stacks consists of on-site sampling of heavy metals on filters for the particulate phase (the most prominent and only fraction considered in this study) prior to subsequent laboratory analysis. Results are therefore known only a few days after sampling. Stiffer regulations require the development of adapted tools allowing automatic, on-site or even in-situ measurements with temporal resolutions. The LIBS (Laser-Induced Breakdown Spectroscopy) technique was deemed as a potential candidate to meet these requirements.

On site experiments were run by melting copper bars and monitoring emission of this element in an exhaust duct at a pilot-scale furnace in a French research center dedicated to metal casting. Two approaches designated as 
indirect and direct analysis were broached in these experiments. The former corresponds to filter enrichment prior to subsequent LIBS interrogation whereas the latter entails laser focusing right through the aerosol for detection. On-site calibration curves were built and compared with those obtained at laboratory scale in order to investigate possible matrix and analyte effects. Eventually, the obtained results in terms of detection limits and quantitative temporal monitoring of copper emission clearly emphasize the potentialities of the direct LIBS measurements.

Keywords: Laser-Induced Breakdown Spectroscopy (LIBS), heavy metals, particles, on-site measurements, foundry

\section{Introduction}

Heavy metals have long been known to be detrimental to human health and the environment. To name but a few examples, exposure to cadmium may lead to kidney and skeletal damage, mercury is liable to produce harmful effects to the lungs and lead is prone to deteriorate both the nervous system and the memory [1]. Pollution of the natural environment is a burning issue as contamination of food and water (e.g. crop and groundwater [1]) may lead to exposure of the population. As a general rule, heavy metals are noxious to soils and waters as they tend to disturb their microbiological activities [1] [2].

Among all the possible pathways of heavy metal emission, the release in the atmosphere is deemed as the most prominent in terms of human health. Most of the sources are mainly of anthropogenic origin. Transports, mining and industries involving combustion processes such as waste processing (incineration) and metallurgy (steel and iron plants, non-ferrous smelters, ferrous and non ferrous foundries) are among the most important sources of such pollution. In this context, regulations have been issued to limit heavy metal emission in the atmosphere. The French act of the 2 February 1998 was enacted to limit emission of various pollutants by industries including heavy metals. The aforementioned act targets most of the industries emitting pollutants with the exception of waste processing (incineration) plants. Threshold values are indicated that were not to be exceeded when the plants are in operation. Table 1 summarizes these French emission value limits and the corresponding elements.

Surveillance of heavy metals implies monitoring and determining their mass concentrations in order to compare the measured values with those of table 1. The current reference method (European Standard EN 14385) consists in collecting heavy metals both in particulate and gas form prior to the analysis using ICP / AES 
or MS (Inductively Coupled Plasma / Atomic Emission Spectroscopy or Mass Spectrometry). Limit values are very likely to be revised downwards in the near future as regulations are bound to become more and more severe. Such hardening of the regulations on the emissions will imply the development of adapted tools. Indeed, the current reference method presents several drawbacks. Samples are to be collected by skilled personnel sent to the designated sites. Then follows their preparation in the laboratory prior to the analysis itself, last step of this time consuming procedure. Several days may indeed elapse between the moment the samples are picked up and that of the obtaining of the results. Considerable amount of time may be gained through the use of an on-site fully automatic technique allowing in-situ and real time analysis of the targeted pollutants. LIBS was deemed as a potential candidate for such purpose and was therefore put to the test for such experiments [3,4].

LIBS consists in focusing a powerful laser pulse on a material (solid, liquid, gas, nanoparticle flow) whose elemental composition is to be determined. The strong heating of the sample at the focusing spot leads to the ignition of a plasma. Simultaneous detection of all the elements the analyzed material is made of is then achieved through optical emission spectroscopy. Being all optical, LIBS is not intrusive and remote or stand-off analyses are even possible. Besides, samples do almost not need preparation. The aforementioned features do make LIBS a promising analytical chemistry method intended to be operated at industrial sites.

LIBS has already been employed for on-site detection of heavy metals in aerosols. Detection may be achieved through two approaches. The first approach known as indirect analysis consists in collecting particles on a substrate (e.g. filter) prior to LIBS interrogation. The second approach designated as direct analysis aims at focusing the laser pulses right through the aerosol, thereby igniting a plasma allowing detection. Indirect [5] and direct [6] [7] [8] [9] approaches have already been put to the test in field experiments in industrial sectors such as waste processing and metallurgy.

The objective of this work is to put to the test the potentialities of direct and indirect LIBS measurements for continuous monitoring of heavy metal emission from industrial plants. In this paper, we report the results obtained with on-site direct and indirect LIBS analyses and compare them with those obtained in a laboratory setting [10]. The attention will exclusively be focused on the detection of heavy metals in particulate form. On-site experiments were carried out with a pilot-scale furnace located in a French research and development center specialized in metal casting (CTIF). A direct LIBS analyzer fitted with a filter enrichment system for subsequent indirect LIBS analysis was implemented along with the reference method described in the European standard EN 14385. All this equipment was connected to the exhaust duct carrying away possible heavy metal emission aspirated through a hood positioned above the furnace. Copper bars were melted in the 
furnace as the latter material was that utilized at laboratory scale. Two calibration curves were drawn both for direct and indirect measurements using the recorded LIBS spectra and the reference measurements. The on-site calibration curves were compared with those obtained in the laboratory in order to investigate possible matrix and analyte effects. Temporal monitoring of copper mass concentration during one of the phases of the melting operations was achieved relying on the direct analysis field calibration curve. Eventually, the obtained on-site detection limit was estimated and discussed and compared with laboratory values.

\section{Foreword}

The melting operations described in this paper were performed using an induction furnace. The latter is a crucible made of silicon carbide with dimensions of about $800 \mathrm{~mm}$ in height and $365 \mathrm{~mm}$ in diameter. A coil through which an alternative electric current passes wraps the furnace generating a magnetic field in it. This fast varying magnetic field will in turn induce an electric current in the metallic mass introduced in the furnace, thereby causing the bars to melt. Gas and particle emissions are aspirated through a hood positioned above the metal bath. Particles and gas flow are then evacuated through a duct and filtered prior to release in the open through the exhaust stack.

The obtaining of a final product (from the metal bars to the molded piece) requires going through four main phases of the melting operations briefly described below:

- The melting phase: the solid metal bars are turned into a metal bath. Materials such as for instance charcoal may be added to the bath to avoid surface oxidation of the metal.

- The holding phase: the metal bath is left still for a while with the aim in view to remove slag and adjust metal composition.

- The adjustment and slagging phase: deoxidizing bars may be added to the bath so as to agglomerate the oxides in the liquid and remove them later on and adjust metal composition.

- The pouring phase: liquid metal is transferred to a ladle first and then in sand molds for the obtaining of the final product

Measurements were carried out only during the first three phases presented above in the framework of the campaign of LIBS experiments. Filter enrichment and LIBS spectrum recording were to comply with the time allotted to the melting operations. Abiding by these constraints in addition to the necessity of minimum enrichment duration of around $40 \mathrm{~min}$ for each filter led to a total of seven sampling points for the whole campaign of experiments (that is to say seven ICP / AES measurements for the reference method). It should be 
noted that LIBS spectra corresponding to the direct approach were continuously recorded while filters were being enriched.

\section{Experimental set-up}

\subsection{On-site general experimental set-up}

The general experimental set-up is presented in figure 1. The experiments were meant to compare laboratory and on-site calibration for both direct and indirect LIBS analyses. The reference method and LIBS measurements were resorted to, to attain this objective. Two sampling lines were required to achieve both LIBS and reference measurements. The same sampling probes utilized for both the LIBS and the reference sampling lines, were those advised in the aforementioned standard.

Sampling was assured drilling two tapping holes through the exhaust duct upstream the filter case. The two orifices were pierced on a horizontal section of the duct, thus allowing sampling on the same streamline. The sampling probes were positioned perpendicularly to the conduit and passed through the drilled apertures. A precautionary distance of 1.5 meters was set between the two orifices so as to avoid measurement difficulties inherent to possible turbulence affecting the sampling point situated downstream the first probe.

The sampling probe consists of a 1.20 meter long glass tube with an inner diameter of around $10 \mathrm{~mm}$. One of its ends is goose neck shaped so that the inlet may face the particle flow to assure sampling. The inner diameter inlet end selection and the flowrate settings within the probe are made so as to assure isokinetic sampling [11]. Constant flow rate of $14.5 \mathrm{lpm}$ was assured using a pump with regulated flow rate. The sampling probe is enclosed in a cylindrical stainless steel sheath tube for its protection.

The sampling probe of the reference sampling line was connected to a filter holder made of glass enclosed in a case. Quartz filters of $75 \mathrm{~mm}$ diameter manufactured by Munktell (Quartz microfiber discs grade MK 360) were employed for the reference measurements. The filter is intended to collect particles so as to allow mass concentration determination of the particulate fraction. Both the stainless steel tube and the case are connected to a temperature controller allowing adjustment of their temperature to that of the particle flow, thereby minimizing particle loss on the walls by condensation. The filter was connected to a thermocouple so that its temperature may be kept constant. The temperature of the gas flow within the exhaust duct happened to be that of ambient air in these experiments, thereby facilitating temperature control. The outlet of the glass filter holder is connected to scrubbing flasks. These contain solutions of $50 \mathrm{ml}$ of a mixture of $4.5 \% \mathrm{HNO}_{3}$ and $1.7 \%$ $\mathrm{H}_{2} \mathrm{O}_{2}$ diluted in water intended to trap and therefore allow the analysis of the gas fraction of the emitted heavy 
metals. Both the filters and the solutions were eventually analyzed through ICP / AES or MS for the determination of mass concentrations in particulate and gas form respectively. The results obtained regarding the gas form were not taken into consideration in this study.

The sampling line of the LIBS set up was connected to the flow cell through which laser pulses are focused for direct LIBS analysis purposes. A filter holder was positioned downstream the cell to collect particles for subsequent indirect LIBS analysis. Quartz filters QM-H (Whatman \& Maidstone, UK) with low metal concentrations were utilized for particle collection. A constant flowrate of $\mathbf{1 4 . 5} \mathbf{~ l p m}$ identical to that of the other line was applied in the course of these experiments.

Both LIBS set ups (direct and indirect) have been described in a previous article [10]. Only a short description of these will be made below.

\subsection{Direct and indirect LIBS set-up}

Direct LIBS measurements were made using laser pulses with energies of $150 \mathrm{~mJ}$ and durations of $5 \mathrm{~ns}$ fired by a $1064 \mathrm{~nm}$ Q-switched laser (Quantel Brilliant) operating at $20 \mathrm{~Hz}$. The laser beam section was spatially expanded to three times the initial diameter and directed toward a dichroïc mirror. It was then focused into the LIBS cell using a $75 \mathrm{~mm}$ focal length lens. Plasma light was collected through the very lens utilized for focusing and focused on the entrance of a $600 \mu \mathrm{m}$ core diameter optical fiber (Ocean Optics) using another $25 \mathrm{~mm}$ focal length lens. Optical emission spectra were retrieved from a spectrometer (iHR320) equipped with a gated intensified CCD camera (Andor iStar model DH734-18F-03).

Indirect LIBS measurements were performed using a Q-switched frequency-quadrupled Nd:YAG laser (Quantel Brilliant B) operating with a repetition rate of $20 \mathrm{~Hz}$ and firing $5 \mathrm{~ns}$ duration pulses with $12 \mathrm{~mJ}$ energy at $266 \mathrm{~nm}$. The optical path geometry was quite close to that utilized for direct measurements. Plasma light emission was collected through a dichroïc mirror and the very lens employed for focusing ( $25 \mathrm{~mm}$ focal length) and focused on the entrance of a $900 \mu \mathrm{m}$ core diameter optical fiber with a $15 \mathrm{~mm}$ focal length lens. The fiber was connected to the entrance slit of a spectrometer (Acton, SP2358i, 600 grooves/mm grating, $0.3-\mathrm{m}$ focal length, $50 \mu \mathrm{m}$ slit width, $\lambda / \Delta \lambda \approx 1200$, resolution FWHM) equipped with an intensified CCD camera (Andor Technology iStar, 2048x512 pixels). 


\section{Results and discussion}

\subsection{Indirect LIBS analysis}

\subsubsection{SEM and EDX analyses on filters}

Filters utilized for LIBS analysis purposes were first examined using SEM (Scanning Electron Microscopy) and EDX (Energy Dispersive X-ray) techniques. Two categories of surface deposits were observed when analyzing the filters using SEM. Three filters out of seven happened to display deposited particles scattered all over the filter surface (figure 2a). Particle size distribution of most of the analyzed particles (about $70 \%$ ) was found to range from 0.5 to $1 \mu \mathrm{m}$ using the SEM. The rest of the particles displayed sizes varying from 1 to $10 \mu \mathrm{m}$. EDX spectrum analyses performed on this first set of filters are presented in figure $2 \mathrm{~b}$. Acquisitions made on isolated particles confirmed that most of these were made of copper. Still, elements such as potassium and to a lesser extent iron were identified as well. SEM analysis of the surfaces of the other four filters of the batch unveiled the presence of a deposit (figure 2c). The corresponding EDX spectra (figure 2d) displayed intense lines of potassium composing the aforementioned layer. Copper lines were not recorded suggesting that the particles were either absent or located beneath the potassium film. Molybdenum and chlorine elements were also identified (molybdenum possibly coming from copper alloy and chlorine from deoxidizing bars or filters). The detection of the potassium layer on four filters out of seven raised the question of its origin. As indicated above, filter enrichment was operated over periods of times spanning all the melting operations but the last one. Filters with potassium layers were found to have been enriched during the phases of melting and adjustment whereas those free of deposits were used in the course of the holding phase. Deoxidizing bars and charcoal happen to have been added to the metal bath during the former two phases. The potassium element is therefore concluded to originate from these operations.

\subsubsection{Spectrum recording procedure and temporal settings}

The analysis of quartz filters using LIBS was investigated and presented in a former article [10]. Filters were scanned by the laser beam according to a matrix of $22 \times 22$ points and a spacing distance of $1 \mathrm{~mm}$ between points. Each spot was interrogated with one single laser shot thereby resulting in the recording of one single spectrum. The $22 \times 22$ spectra were eventually ensemble-averaged in one final spectrum. Selection of the atomic lines was made taking into account self-absorption effects evidenced in previous experiments [10]. Details on all the line characteristics cited in this paper may be found in reference [12]. The $521.82 \mathrm{~nm}$ copper line was 
favored at the expense of the well known 324.754 and 327.396 lines, the latter two being more prone to selfabsorption than the former. Possible interference of the line of interest with chromium ionic line was evidenced, thereby emphasizing the need for a spectrometer with adequate resolution. The presence of chromium raises the question of its origin, the latter element being not known as a constituent of charcoal. Chromium was therefore concluded to originate from the residue of a previous melting in the same furnace. As to the temporal settings, time delay and gate width of $100 \mathrm{~ns}$ and $1 \mu$ s respectively were selected according to previous experiments [10].

\subsubsection{On-site calibration}

The LIBS calibration curve for filter analysis was built using the seven ICP/AES measurements as reference concentrations. These yield the mass of the targeted element per filter. The surface concentration $\left(\mu \mathrm{g} / \mathrm{cm}^{2}\right)$ of the LIBS filters may be determined knowing their effective enrichment surfaces and the flow rates of both the sampling lines of the reference and LIBS methods. Thenceforth, an on-site calibration curve was built as may be seen in figure 3. The latter was drawn normalizing copper line intensities with the silicon atomic line at around $505.8 \mathrm{~nm}$ (Si line at $252.85 \mathrm{~nm}$ at the second order) of the matrix. This usual precaution was taken so as to reduce possible fluctuations of the LIBS signal. Variations of laser energy may indeed alter the ablated mass, thereby affecting the signal [10]. Standard deviation was calculated over the 22 individual spectra constituting the final averaged spectrum. Examination of the obtained calibration curve clearly shows that the seven points do not align. Such behavior may be the signature of matrix effects. With the idea in mind to check this assertion, cross-checking of the SEM / EDX analyses with LIBS results was performed. Four points out of seven found to correspond to filters smeared with potassium did eventually prove to be aligned. And so did the last three corresponding to scanning on filters free of the potassium layer. This observation led to plot two calibration curves displaying two straight lines with different slopes. This result evidences the issue of matrix effects when collecting particles under field conditions. Alteration of the matrix like for instance potassium deposition on the filters clearly leads to a loss of sensitivity like that displayed by four points of the graph of figure 3. Further examination of these two curves shows that they do not bend for the largest concentrations, thus demonstrating that the $521.82 \mathrm{~nm}$ line is less prone to lead to self absorption than the 324.754 and $327.396 \mathrm{~nm}$ lines in this concentration range [10].

Eventually, these results illustrate the difficulties of the indirect LIBS measurement approach under field conditions using filters. The strong matrix effects occurring under indirect analysis sound like a real hindrance to validate this approach in the context of these experiments. The loss of sensitivity induced by the 
potassium deposit is blatant. Consequently, further studies and more sophisticated calibration schemes should be used to overcome the encountered difficulties.

\subsection{Direct LIBS analysis}

\subsubsection{Spectrum recording procedure and temporal settings}

When scanning a filter or analyzing a solid, each laser shot interacts with the analyte, thereby inclining to ensemble-average all the recorded spectra to obtain a final robust spectrum. The discrete nature of the particles and the stochastic character of LIBS analysis leads to the use of an alternative data processing method first proposed by Carranza and Hahn [13] and named conditional analysis. It consists in recording individual spectra, each of them corresponding to one unique laser shot. The ratio of the number of spectra having sampled one particle (spectra therefore considered as positive) to that of the total amount of laser shots fired [14] yields the hit rate which when expressed as a percentage denominates as the particle sampling rate (PSR). Spectra free of signal are discarded prior to the addition leading to the final spectrum. The latter is obtained by adding the intensities of all the positive spectra and multiplying the resulting sum by the hit rate. Conditional analysis was applied to the $324.754 \mathrm{~nm}$ and $327.396 \mathrm{~nm}$ copper lines. About eighteen series of one thousand shots, each shot corresponding to a single spectrum were recorded. Spectrum acquisitions were set to cover the whole duration of both reference and LIBS filter enrichment. A titanium line was found that could possibly interference with the most sensitive line of interest at $324.754 \mathrm{~nm}$. Nevertheless, the impact of such effect should be moderated by the low frequency (less than 10\%) of the titanium line emergence. Time delay and integration time were identical to those selected in the laboratory experiments $[10,15]$ and therefore set to $30 \mu$ s and $80 \mu$ s respectively.

\subsubsection{Comparison of on-site and laboratory calibrations}

The average mass concentrations flowing through the LIBS cell may be calculated by determining the surface concentrations inferred from the reference method using the following formula:

$$
C_{m}=\frac{C_{s} S}{Q \Delta t} \quad \text { Equation } 1
$$

where $C_{s}$ is the surface concentration calculated in section 4.1.4, $S$ the effective enrichment surface of the LIBS filters, $Q$ the flow rate in the LIBS sampling line and $\Delta t$ the enrichment time.

The calibration curve was built using the most sensitive of the two lines, namely that at $324.754 \mathrm{~nm}$ (figure 4). Only six series of spectra were recorded, though as mentioned above 7 filters were enriched. 
Examination of the field calibration curve shows that the LIBS intensity increases with increasing mass concentration. One of the points did not follow this tendency for an unknown reason and was therefore not utilized for subsequent calibration. The curve is seen to bend for the largest mass concentrations. This slight inflexion may have two possible causes. It may be caused by self-absorption bearing in mind that $324.754 \mathrm{~nm}$ is a resonant line. Possible incomplete vaporization of large particles with sizes approximately greater than $7 \mu \mathrm{m}$ (copper upper particle size beyond which complete vaporization does not occur) may also account for the observations [10]. Incomplete vaporization may indeed bring about saturation of the LIBS signal.

The field and laboratory curves were found to superimpose quite well. This result raises questions as to the apparent absence of matrix and analyte effects. When analyzing aerosols using direct LIBS, the matrix relates to the gas where the laser-induced plasma is ignited whereas the analyte pertains to the particles. Thus, change of the matrix and to a lesser extent in the analyte is expected to modify plasma temperature and electronic density. Accordingly, significant change in matrix or analyte composition occurring for instance when moving from the laboratory to the field may affect the LIBS signal rendering laboratory-made calibration curves useless. In field experiments, the matrix was approximately the same as that encountered in laboratory conditions, namely the air. In addition, the air sucked in the exhaust duct by the hood positioned above the furnace was not found to carry much dust. No significant dust deposits were observed on the inner faces of the LIBS cell windows. Therefore, the laser-induced plasma ignited in both the laboratory and the exhaust duct is expected to exhibit identical characteristics, thereby making possible matrix effects improbable. There remains the eventuality of analyte effects. Particles containing copper originating either from the metal bath or from a generator are not likely to be of the same composition. Thus, as calibration curves do not depart from each other, the analyte effects, if any, are not that significant at least in the framework of these experiments.

\subsubsection{Quantitative temporal monitoring of copper particulate emission}

Quantitative temporal evolution of the LIBS signal obtained during one of the phases of melting is presented in figure 5. This temporal evolution was obtained from a linear fit of the calibration curve. Each point corresponds to a LIBS spectrum obtained according to the procedure explained in section 4.2.1. The $324.754 \mathrm{~nm}$ line was retained for that purpose as it was utilized for calibration. Several points were found to display LIBS intensities outweighing those of the calibration curve. These could therefore not be represented on the quantitative temporal evolution (grey rectangle zones where mass concentrations would be higher than 180

$\left.\mu \mathrm{g} / \mathrm{m}^{3}\right)$. The obtained mass concentration is seen to decrease with a steep slope within time duration of around 
twenty minutes. Such drop in LIBS signal could be accounted for bearing in mind that LIBS recording was started shortly after charcoal addition to the metal bath during the melting phase. The LIBS intensity drop is obviously related to the decrease in mass concentration of the probed aerosol. A sudden rise of the signal (mass concentrations out of range (second grey rectangle)) was attributed to metal bath stirring performed by the operator in charge of the melting operations. It then stabilizes up to the end of LIBS recording during this phase. Thus, mass concentration of copper particles was assessed to amount to around $25 \mu \mathrm{g} / \mathrm{m}^{3}$ when entering the holding phase. Eventually, the obtained results demonstrate the potentialities of LIBS applied to quantitative particle monitoring in industrial processes.

\subsubsection{Rough estimation of the detection limit for direct LIBS analysis}

The calculation of the limit of detection was attempted in spite of the scarcity of the data inherent to the limited allotted time dedicated to these experiments. The detection limit may be calculated resorting to the confidence band method [16]. Still, the unique and limited series of points constituting the backbone of the calibration curve of figure 4 does not favor the obtaining of a reliable value. Nevertheless, the limit of detection was computed so as to assess its order of magnitude and compare it to that determined at laboratory scale. The calibration curve was seen to bend (for reasons explained above) when integrating the last point corresponding to the largest mass concentration. This point was withdrawn for the calculation to ensure linearity of the calibration curve and therefore comply with calculations resorting to the confidence band method. A detection limit of around $20 \mu \mathrm{g} / \mathrm{m}^{3}$ was calculated whereas that derived from laboratory experiments did amount to around $15 \mu \mathrm{g}$ $/ \mathrm{m}^{3}$. Both detection limits are therefore found quite close to each other which sounds consistent with the quite satisfying superimposing of the points of both field and laboratory experiments observed in figure 4 .

\section{Conclusion}

Direct and indirect LIBS analyses have been implemented in a French research center specialized in metal casting. Copper bars were melted in a furnace surmounted by a hood allowing sucking in emissions from the metal bath through a duct up to the exhaust stack. Copper was selected for this on-site trial as the latter element had already been used for laboratory experiments reported in a previous article, thus allowing comparison of field with laboratory results. A transportable LIBS analyzer allowing direct analysis equipped with a filter enrichment system for subsequent indirect analysis was connected to the exhaust duct along with the equipment necessary for reference method implementation as described in the European standard EN 14385.

Part of the stream flowing through the exhaust duct was diverted towards the two aforementioned set-ups via 
sampling lines designed for standardized measurements. Thenceforth, calibration curves were built that correspond to indirect and direct analyses exploiting the recorded LIBS spectra and the copper mass concentrations measured through the reference method.

Points obtained through indirect analysis were found not to align suggesting possible matrix effects. Two calibration curves eventually inferred from these experiments were found to correspond to two sets of filters. The first set was revealed to be smeared with a potassium layer through SEM / EDX analysis whereas filter surfaces of the second set was found free of this element. The calibration curve of lesser slope suggested a loss of sensitivity attributed to the aforementioned deposit. Such result emphasizes the difficulties inherent to LIBS measurements using analyte collection on filters. The number of points did not incline to calculate a detection limit as the latter may be quite inaccurate.

Points recorded for direct calibration curve elaboration displayed contrariwise a satisfying alignment. This observation suggests that matrix and analyte effects, if any, are rather insignificant in the framework of these experiments, thereby allowing exploiting these calibration results to make quantitative temporal evolution of copper mass concentration in the course of one of the phases of the melting operations. Eventually, though the number of points was not that high given the limited allotted time for these field experiments, the detection limit derived from the field calibration curve were computed for comparison with those obtained in laboratory. Though roughly estimated owing to the small number of points on the graph, laboratory and field detection limit values were found of the same order of magnitude with $15 \mu \mathrm{g} / \mathrm{m}^{3}$ and $20 \mu \mathrm{g} / \mathrm{m}^{3}$ respectively.

Thus, the feasibility of on-site direct LIBS analysis is therefore evidenced as the laboratory made calibration curve proved to be exploitable in the field. Future experiments are intended to build new calibration curves including the rest of the heavy metal elements reported in the list. Direct LIBS analysis may potentially meet the needs of industrial facilities requiring on-line real time monitoring of pollutants to comply with current and future regulations. A new on-site campaign of experiments with a larger amount of data could be envisaged to consolidate these promising results.

\section{Acknowledgments:}

This research was funded by the French Environment and Energy Management Agency (ADEME) under contract number 0874C0135. We would like to thank M. Emmanuel Fiani from ADEME for his support in the course of this project. We would also like to thank Jean Poulleau and Serge Collet from the department of air emissions at INERIS for the fruitful discussions we had and the CTIF personnel in charge of the handling of the 
furnaces. We are grateful to Robin Aujay from the department of metrology at INERIS for his assistance when carrying out TEOM measurements prior to field experiments.

\section{References}

[1] L. Järup, Hazard of heavy metal contamination, British Medical Bulletin 68 (2003) 167-182

[2] O. Lindqvist, Environmental impact of mercury and other heavy metals, J. of Power Sources 57 (1995) 3-7

[3] D. W. Hahn and N. Omenetto, Laser-Induced Breakdown Spectroscopy (LIBS), Part I: Review of Basic Diagnostics and Plasma-Particle Interactions: Still-Challenging Issues Within the Analytical Plasma Community, Appl. Spectrosc. 64 (2010) 335A-366A

[4] D. W. Hahn and N. Omenetto, Laser-Induced Breakdown Spectroscopy (LIBS), Part II: Review of Instrumental and Methodological Approaches to Material Analysis and Applications to Different Fields, Appl. Spectrosc. 66 (2012) 347-473

[5]. R.E. Neuhauser, U. Panne, R. Niessner, Laser-induced plasma spectroscopy (LIPS): a versatile tool for monitoring heavy metal aerosols, Analytica Chimica Acta 392 (1999) 47-54

[6] S.G. Buckley, H. A. Johnsen, K.R. Hencken and D. W. Hahn, Implementation of laser induced breakdown spectroscopy as a continuous emissions monitor for toxic metals, Waste Management 20 (2000) 455-462

[7] D.W. Hahn, W. L. Flower and K. R. Hencken, Discrete particle detection and metal emissions monitoring using Laser-Induced Breakdown Spectroscopy, Appl. Spectrosc. 51 (1997) 1836-1844

[8] H. Zhang, F. Y. Yueh and J. P. Singh, Laser-Induced Breakdown Spectrometry as a multimetal continuousemission monitor, Appl. Optics 38 (1999) 1459-1466

[9] R.E. Neuhauser, U. Panne, R. Niessner and P. Wilbring, On-line monitoring of chromium aerosols in industrial exhaust streams by laser-induced plasma spectroscopy (LIPS), Fresenius J. Anal. Chem. 364 (1999) 720-726

[10] G. Gallou, J.B. Sirven, C. Dutouquet, O. Le Bihan and E. Frejafon, Aerosols Analysis by LIBS for Monitoring of Air Pollution by Industrial Sources, Aerosol Sci. and Technol. 45 (2011) 908-916

[11] P. A. Baron and K. Willeke, «Aerosol measurement, principles, techniques and applications » second edition, Wiley 2005

[12] Lines on line. http://physics.nist.gov/PhysRefData/ASD/lines_form.html

[13] J. E. Carranza, D. W. Hahn, Sampling statistics and considerations for single-shot analysis using laserinduced breakdown spectroscopy, Spectrochim. Acta Part B. 57 (2002) 779-790 
[14] P. K. Diwakar, K. H. Loper, A.-M. Matiaske, D. W. Hahn, Laser-induced breakdown spectroscopy, for analysis of micro-and nanoparticles, J. Anal. At. Spectrom. 27 (2012) 1110-1119

[15] T. Amodeo, C. Dutouquet, O. Le Bihan, M. Attoui, E. Frejafon, On-line determination of nanometric and sub-micrometric particle physicochemical characteristics using spectral imaging-aided Laser-Induced Breakdown Spectroscopy coupled with a Scanning Mobility Particle Sizer, Spectrochim. Acta Part B 64 (2009) $1141-1152$

[16] J.M. Mermet, Limit of quantitation in atomic spectrometry: an unambiguous concept? Spectrochim. Acta Part B 63 (2008) 166-182

\section{Figure captions}

Figure 1. On-site experimental set-up

Figure 2. Analysis of particles collected on filters with SEM images of (a) filter with copper particle deposition (c) filter smeared with potassium deposit and EDX spectra of (b) filter with collected copper particles (d) filter with potassium deposit

Figure 3. Red line and green line calibration curves obtained when analyzing filters with and without potassium respectively. The green line calibration curve evidences the loss of sensitivity caused by the potassium deposit.

Figure 4. Calibration curves obtained (red line) at laboratory and (black line) in the field using the $324.754 \mathrm{~nm}$ copper line

Figure 5. LIBS Quantitative temporal evolution of copper concentration in the course of the melting operations. Grey rectangles correspond to mass concentrations higher than $180 \mu \mathrm{g} / \mathrm{m}^{3}$ (maximum of the calibration curve) and therefore not represented on the graph

\section{Table caption}

Table 1. Emission value limits of the French act of the $28^{\text {th }}$ of February 1998 
Table 1 .

\begin{tabular}{l|l}
\hline HEAVY METAL & EMISSION LiMITS \\
\hline $\mathrm{Cd}+\mathrm{Tl}+\mathrm{Hg}$ & $0.1 \mathrm{mg} / \mathrm{Nm}^{3}$ for an emission rate larger than $\mathrm{g} / \mathrm{hour}$ \\
$\mathrm{Hg}$ & $0.05 \mathrm{mg} / \mathrm{Nm}^{3}$ for an emission rate larger than $1 \mathrm{~g} / \mathrm{hour}$ \\
$\mathrm{Pb}$ & $1 \mathrm{mg} / \mathrm{Nm}^{3}$ for an emission rate larger than $10 \mathrm{~g} / \mathrm{hour}$ \\
$\mathrm{As}+\mathrm{Se}+\mathrm{Te}$ & $1 \mathrm{mg} / \mathrm{Nm}^{3}$ for an emission rate larger than $5 \mathrm{~g} / \mathrm{hour}$ \\
$\mathrm{Co}+\mathrm{Cr}+\mathrm{Cu}+\mathrm{Mn}+\mathrm{Ni}+\mathrm{Sb}+\mathrm{Zn}+\mathrm{V}$ & $5 \mathrm{mg} / \mathrm{Nm}^{3}$ for an emission rate larger than $25 \mathrm{~g} / \mathrm{hour}$ \\
\hline
\end{tabular}

\section{HIGHLIGHTS}

- The LIBS technique was applied to heavy metal particle monitoring in a foundry duct

- LIBS analysis was made both on filters and directly on the particle flow

- Analysis on filters displayed matrix effects

- Direct analysis on the particle flow did not display matrix effects

- The detection limit in the field was close to that determined in the laboratory 


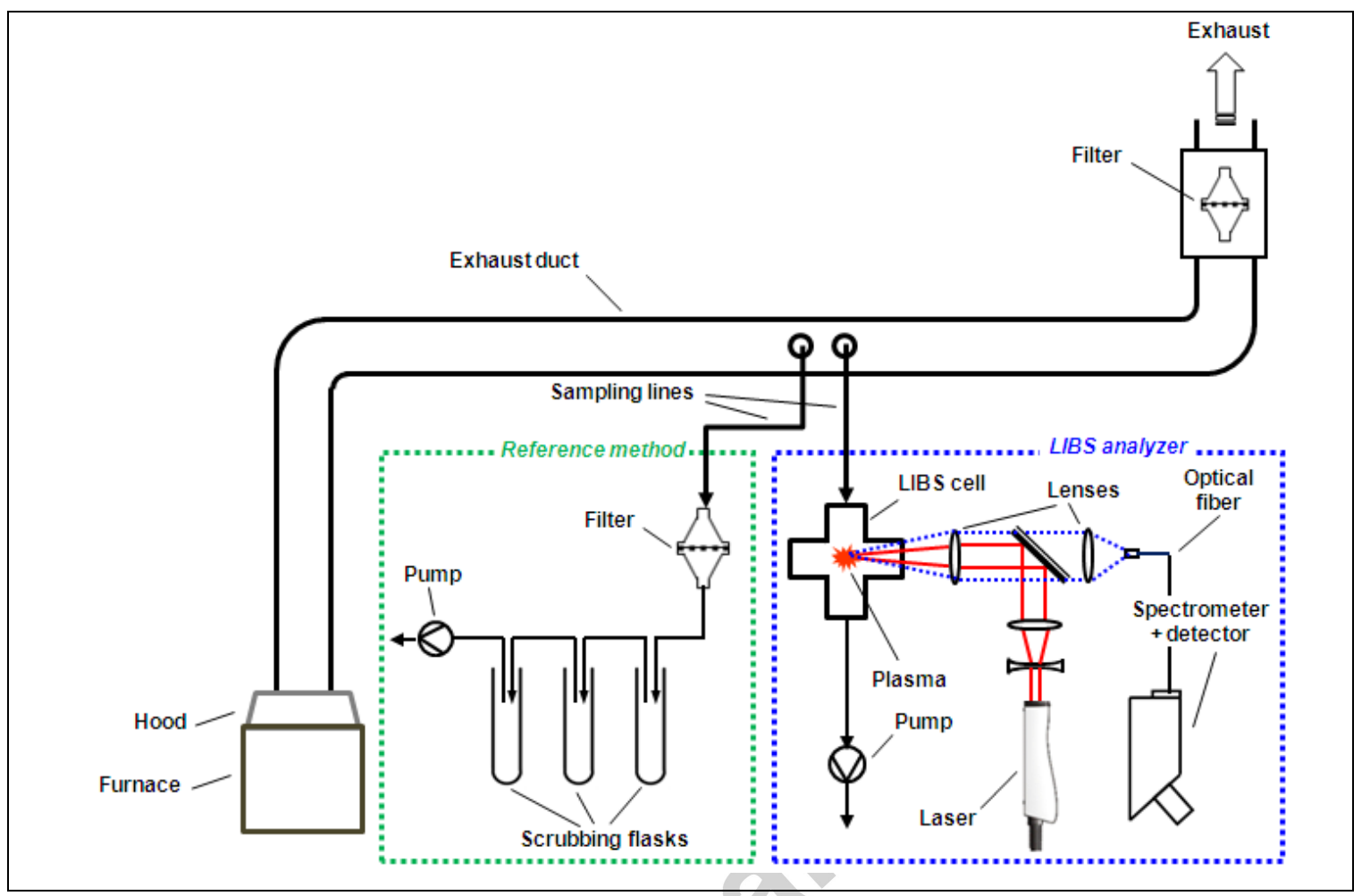

Figure 1
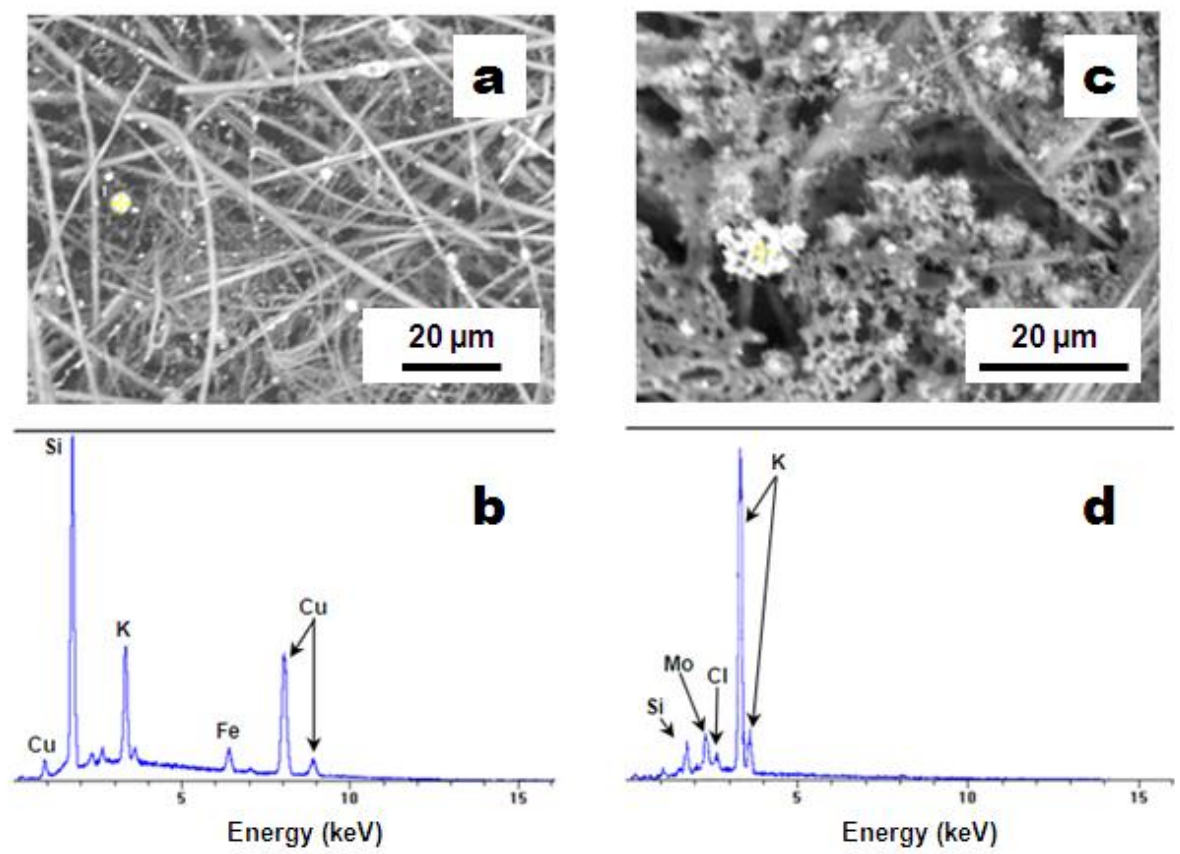

Figure 2 


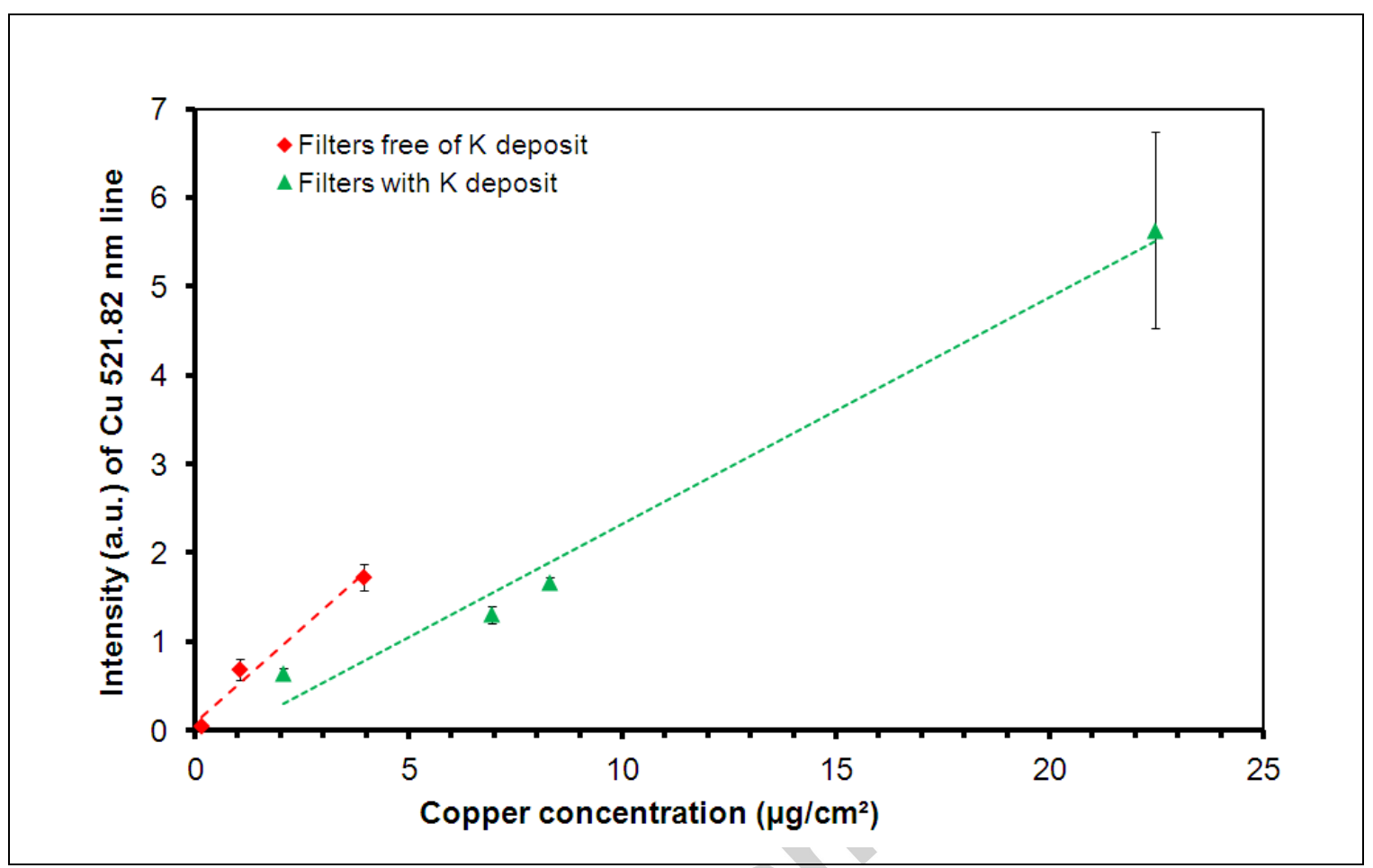

Figure 3

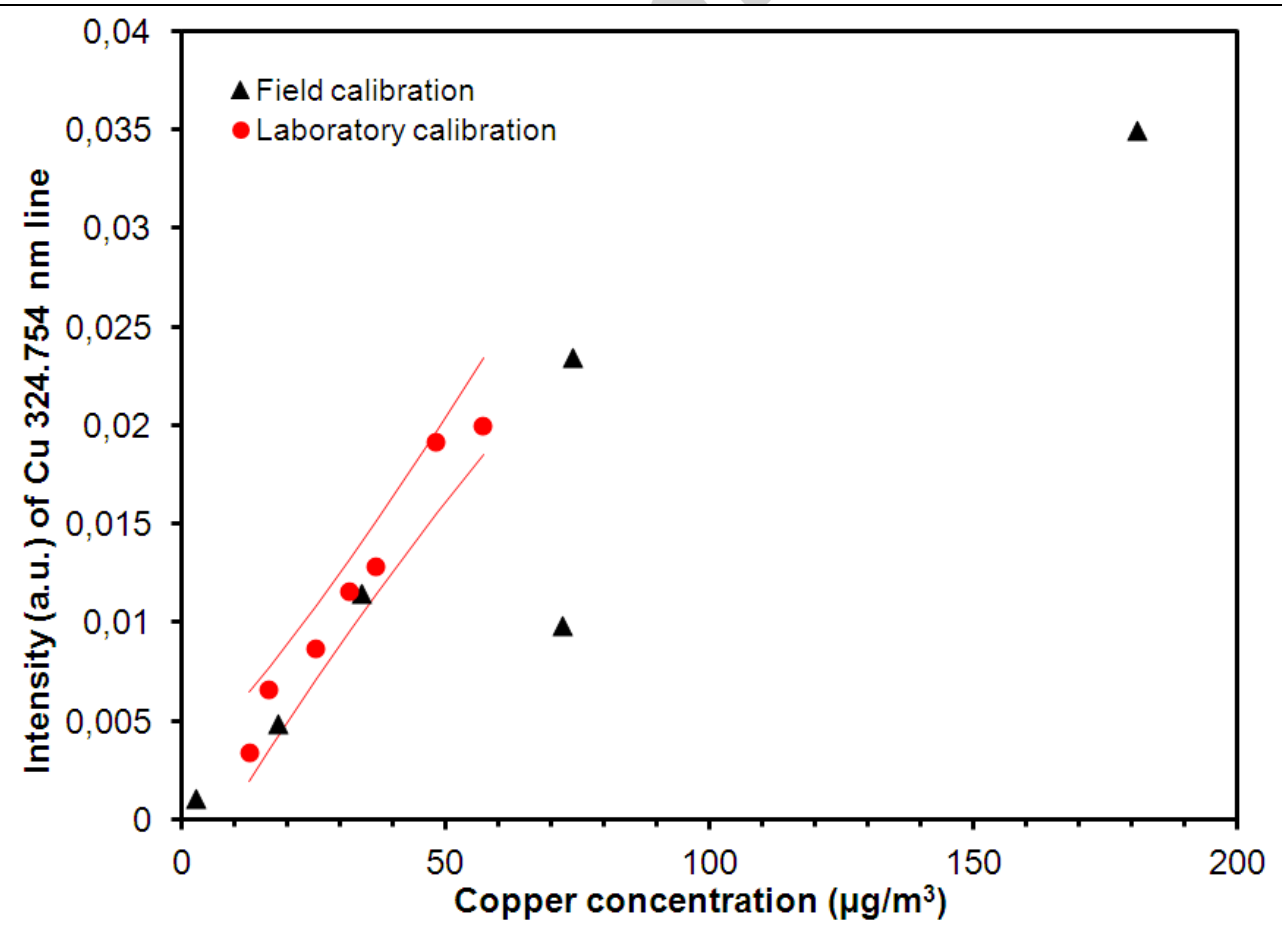

Figure 4 


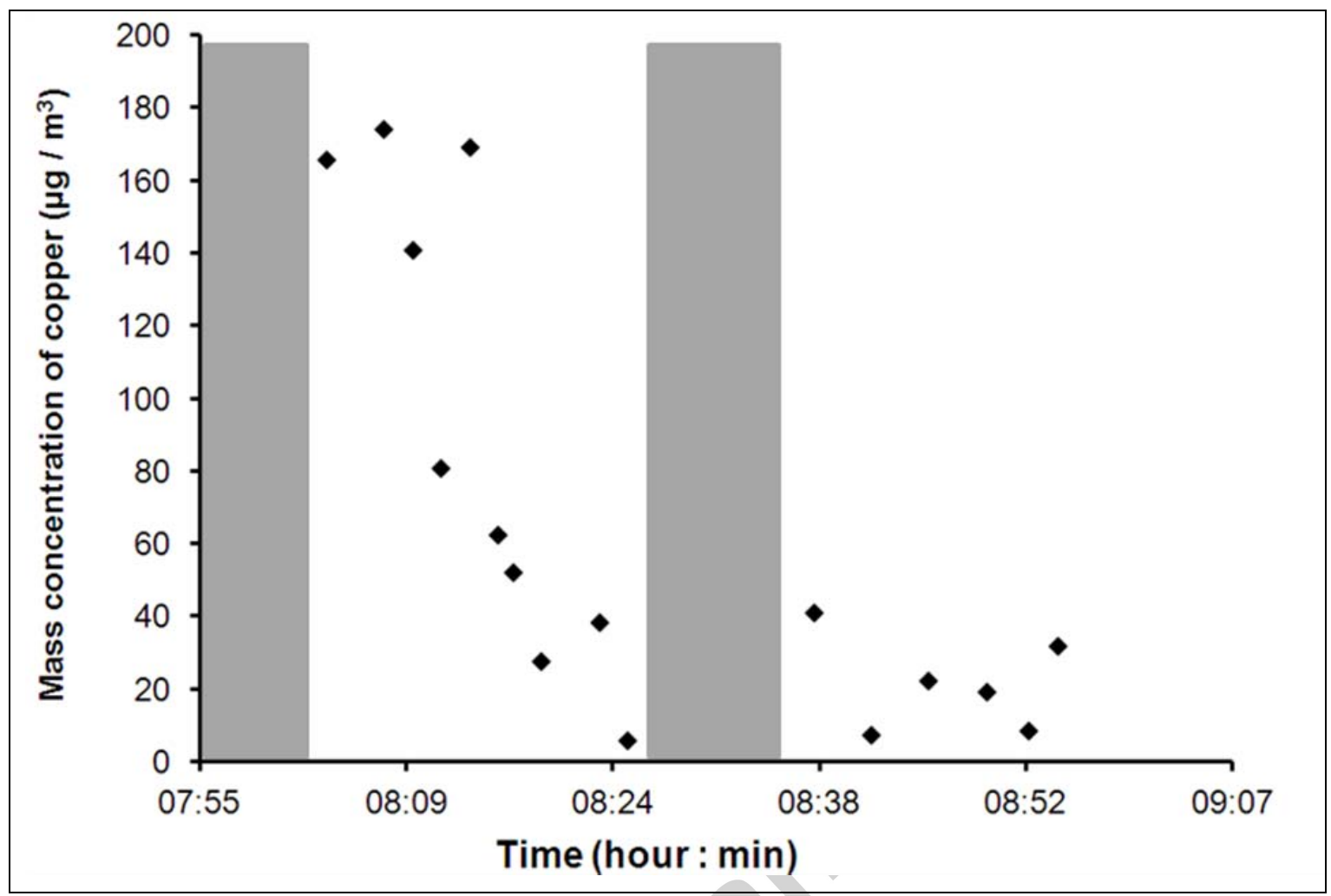

Figure 5 


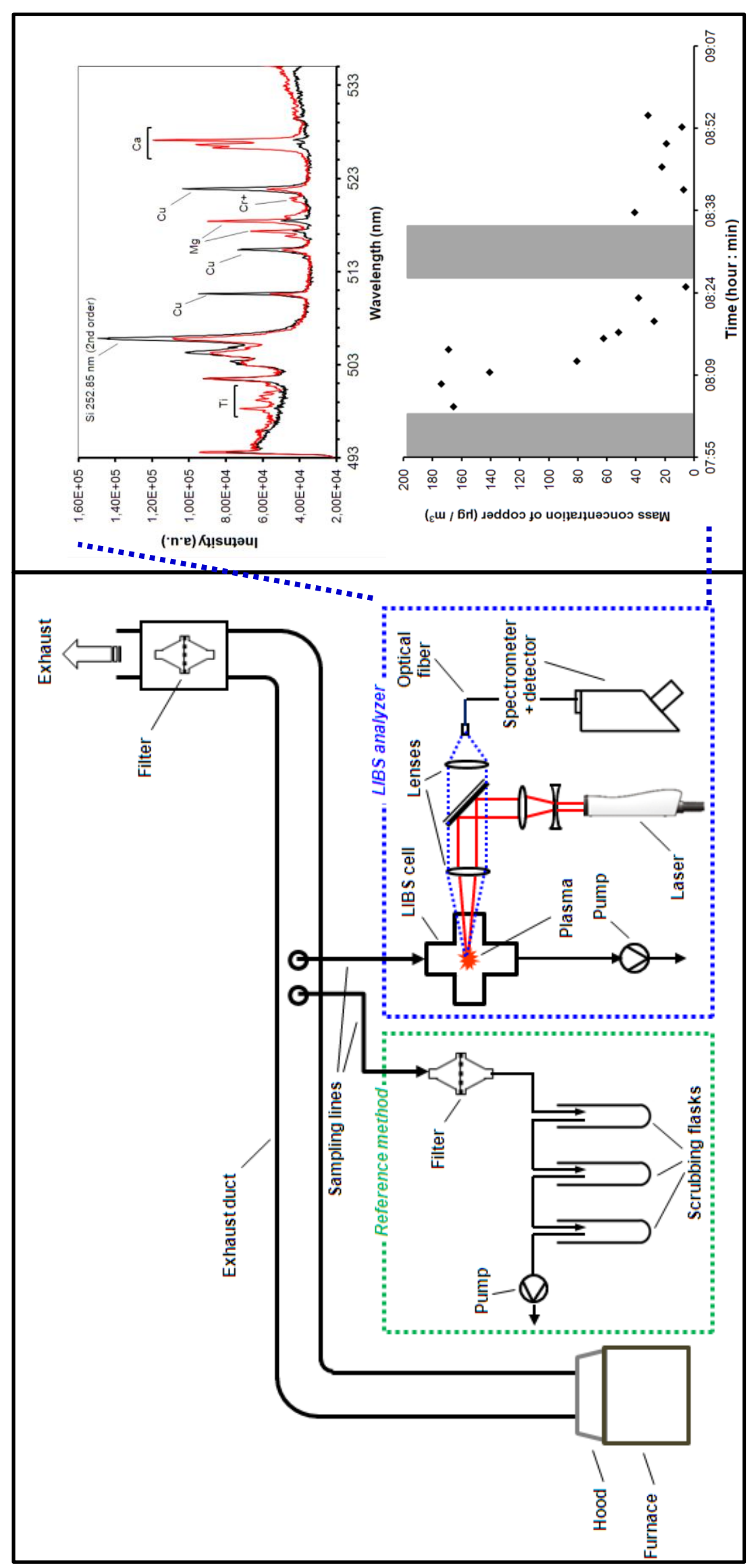

